\title{
Batman en Chile o la deformación histriónica de un mito
}

\section{Batman in Chile or the histrionic deformation of a myth}

Daniel Rojas Pachas

Universidad de Tarapacá, Arica. Chile.

carrollera@hotmail.com

\section{Resumen}

Este trabajo se propone analizar la novela Batman en Chile de Enrique Lihn priorizando la resemantización que realiza el autor chileno del mito heroico al hacer uso de estrategias textuales como la ironía, el humor conceptual, referencias intertextuales a la cultura pop, explotación del mal gusto y el kitsch a fin de crear un híbrido que tensione el panorama narrativo nacional como la retórica de su contexto de producción y la guerra fría en Latinoamérica.

Palabras clave: semántica, kitsch, ironía, intertextualidad, cómic.

\begin{abstract}
The current research intends to analyze Enrique Lihn's novel Batman en Chile. The work studies the relevance of the heroic myth's resemantization (in the sense of deconstruction, of reconfiguration and/or of reaffirmation) produced by the use of textual strategies as irony, conceptual humor, intertextual references from pop culture and the abuse of bad taste and kitsch esthetics, intended to create a hybrid that placed a strain in the Chilean narrative and also explores the rhetoric of his productive context and the cold war in Latin America.
\end{abstract}

Keywords: Semantics, Kitsch, Irony, Intertextuality, Comic. 


\section{Introducción}

La siguiente lectura de la obra de Enrique Lihn aborda su trabajo como narrador, específicamente se estudia la novela Batman en Chile, Ediciones La Flor (Argentina 1973) re-editada por Ediciones Bordura (Chile 2008). Se prioriza la resemantización que el autor chileno da a la figura mítica de Batman, icono pop del comic norteamericano y parte crucial del universo DC.

\section{Batman el mito ante la mirada de Enrique Lihn}

No podemos ignorar que el cine y televisión de la década del sesenta atenuó la tensión psicológica de Batman como actante y más aún su conflicto político, si pensamos se trata de un sujeto que desde su origen y motivaciones desafía a su entorno. No olvidemos que Batman es un vigilante portador de una visión punitiva de la justicia (la llamada razón de estado ${ }^{1}$ ). Atributos que se remontan al asesinato de los padres de su alter ego, Bruce Wayne y la venganza consecuente como móvil de su lucha contra el crimen y justificación del grado de violencia al que puede llegar en sus mecanismos de coerción. Recordemos dos de las aclamadas versiones del personaje, y que han moldeado posteriores relecturas y traspasos del vigilante enmascarado a otros medios. Ambas historias de Frank Miller, la primera Year one, nos muestra un joven e inexperto Batman lidiando con la carga de ser un héroe rechazado por la sociedad debido a los métodos abusivos que elige para infundir temor al crimen, el paralelo lo impone la figura policial de Gordon, un hombre correcto y agente de la ley encargado de apresar a Batman, sin embargo, a causa de la brutalidad de la ciudad, los dos detectives evolucionan y se ven forzados a confiar el uno en el otro y llegar a un punto de encuentro en sus métodos de imponer justicia. En Dark Knight Returns, un envejecido y retirado Batman retorna a su cruzada por salvar a Gotham City y enfrenta una amenaza mutante armando un ejército anarquista que termina por desestabilizar a todo el gobierno norteamericano, y termina batiéndose a costa de su propia vida, a duelo con el más poderoso agente del gobierno norteamericano y guardia personal de Ronald Reagan, Superman.

Lihn en su novela, se enfoca de modo visionario en la figura del encapuchado y retorna al mito original, se apropia de los múltiples contenidos y sub-lecturas y los

1 "Cuando se trata de la salvación de la patria, hay que olvidarse de la justicia o de la injusticia, de la piedad o de la crueldad, de la alabanza o del oprobio y, dejando de lado toda consideración ulterior, es necesario salvar a la patria, con gloria o con imaginación." (Maquiavelo, "Discursos sobre la primera década de Tito Livio" 105). Respecto a Batman, José Ramón Narváez Hernández nos señala: "Batman es capaz de resistir esta persecución porque conoce el mal, porque lo mueve la venganza y por tanto es el más apto para decidir cuándo utilizar la violencia a favor de ciudad Gótica, es el lado obscuro de la justicia, la razón de Estado que necesita del estado de excepción para poder obrar con rapidez y eficacia” (Narváez, "Razón de estado y razón de justicia”). 
desvirtúa con fines críticos y exploratorios pues al replantearse la iconicidad de Batman como signo situado en un contexto extraño o extranjero, expone nuevas dimensiones y lecturas que recién a mediados de los setenta Dennis O'Neil y Neal Adams, autores de DC, guionista/editor y dibujante respectivamente asumen al dar un revival al personaje y ubicarlo en un entorno rodeado por conflictos contraculturales, reviviendo la visión pulp y noir de los inicios del comic en los años cuarenta, junto a temas como el racismo, la drogadicción y la disidencia política, lo cual se concretiza en los ochenta con la visión más madura que del caballero oscuro podemos dar cuenta a la fecha, me refiero a la ya mentada versión de Miller en Dark Knight Returns.

Para efectos del carácter mítico podemos destacar la valoración Dionisiaca de Batman. Saúl Lázaro Altamirano destaca esta situación en su artículo "El mito trágico de Batman" por tanto utilizaré su visión en esta materia, como directriz argumentativa de mi estudio:

Batman es uno de los "héroes míticos de cómics", por lo tanto guarda la esencia e identidad del mito trágico: Dionisio. En el Origen de la tragedia, Nietzsche explica que detrás de los héroes trágicos como Prometeo o Edipo se encuentra Dionisio. Dionisio, aparece en una pluralidad de figuras bajo la máscara de un héroe que combate y que se encuentra al mismo tiempo enlazado con los restos de la voluntad particular [...] El elemento dionisiaco acentúa lo vacuo y como muchos otros héroes que mantienen una doble identidad, Batman encuentra parte de su tragedia en no mantener una vida normal, por el contrario, ésta es absorbida por su identidad de héroe. El deber del héroe se impone ante el del sujeto (192).

Esta mirada dual del personaje, la podemos graficar en las personalidades opuestas pero complementarias de Batman y Bruce Wayne, uno el héroe oscuro, el otro su alter ego, un millonario playboy. Lihn explota ambas, y a su vez satiriza la connotación simbólica del personaje al dotarlo de un discurso pragmático y retórica de la democracia norteamericana del periodo de la guerra fría. Posición que Lihn expone en los siguientes términos:

[...] lucían, junto a las cincuenta estrellas, los oscuros y radiantes mitos que estaban en la base de la Gran Sociedad y de su crecimiento incontenible: el Mayflower cargado de profetas y de santos que se arrojaban, con heroica voracidad, a la conquista de la Tierra Prometida, contra los rojos emplumados de su tiempo: el Lejano Oeste atravesado por los disparos de los pioneros contra los enemigos de la libertad y la abundancia para todos; la justa derrota de los estados sureños con que el Señor premiaba el norte industrial, convirtiéndolo en el cuerpo y en el alma del país, y los negocios son los negocios, baby (17).

Lectura del arquetipo heroico que no es totalmente ajeno a la naturaleza que especialistas en Batman y estudiosos de las relaciones entre cultura e imagen simbólica le 
reconocen al enmascarado justiciero. Umberto Eco por ejemplo nos dice al respecto: "El personaje mitológico de los cómics se halla actualmente en la situación de ser un arquetipo, la suma y compendio de determinadas aspiraciones colectivas, y por lo tanto debe inmovilizarse en una fijeza emblemática que lo haga fácilmente reconocible" (Apocalípticos e integrados 229).

En el mismo sentido John Darowski agrega:

Fuera de toda la adversidad, los Estados Unidos se las ha arreglado para crear un largo corpus de mitos nacionales que suplen a través de su exceso de popularidad la falta de coherencia. Una de las líneas míticas, alcanza su culminación en Batman y los superhéroes. En adición se prefigura ante la imagen de un viejo mito y tradiciones, el contenido de un arquetipo del nuevo mundo en que se prioriza la rudeza individual y los elementos contradictorios del sueño americano, los ideales del hombre que se hace a sí mismo, la fe en la sociedad y a la par la pesadilla o distopía americana a través de Gotham (34).

Podemos destacar que gracias a Batman en Chile el autor nacional indaga en las tensiones políticas y psicológicas de su contexto, el Chile de la Unidad Popular y su consecuente oposición. Sobre todo se enfoca en la paranoia intelectual de autoridades y pensadores, asimismo importa la ambigüedad en el proceder y discursear de ambos bandos ideológicos. Para lograr su cometido edifica el texto de manera lúdica, tal como señalan los títulos alternativos de la obra, El ocaso y soledad de un ídolo yanqui en su lucha contra el desierto rojo.

A juicio personal estamos ante un producto cultural híbrido, una rareza conceptual que se aparta considerablemente de la narrativa de su generación y establece un nexo satírico con el noveno arte y el género de superhéroes sin caer claro está, en la pobreza y superficialidad de la estética de Batmania. Me refiero a la producción norteamericana de los años sesenta en que un joven Adam West interpretaba a Batman y su alter ego. La mirada del estudio, impuso una impronta juvenil y a go-go, propia de la cultura pop de la época, al traspasar elementos del lenguaje del comic a la pantalla chica con estridentes bailes de los protagonistas, exceso de colores fluorescentes en la escenografía, onomatopeyas que irrumpían las escenas de acción y villanos sobreactuados. Esta versión, aún pesa sobre el personaje y la percepción infantil y trivial que la gran masa de público sostiene, sobre todo la impresión que los profanos guardan sobre la totalidad de la ficción sin reconocer sus rasgos subyacentes. Lihn supera y se impone a esta versión por medio de la exageración y la ironía y la lleva a otros planos, desde el mal gusto y la banalidad prioriza la exploración de los anversos reflexivos del mito.

En este sentido se pueden mencionar otras aproximaciones más detalladas y enrevesadas de la psicología de Batman, como ocurre en la serie regular de La Liga de la Justicia, a cargo de Mark Waid en la historia La Torre de Babel (DC, 2000) en la cual se da un giro al personaje proveyéndole de una agenda secreta en la cual guarda 
armas y documentos que eventualmente puede llegar a usar contra sus pares (todos son mutantes o alienígenas). Superman (extraterrestre) Mujer Maravilla (Amazona) Flash (mutante), y él como único humano dentro del universo DC asume dicha responsabilidad. Por último, hay que mencionar a Alan Moore, autor de V de Vendetta y Watchmen (dos de los comics más importantes de los últimos cincuenta años), quien también provee al lector de una mirada particular del hombre murciélago dotada de desviaciones patológicas. The Killing Joke ilustrada por Brian Bolland, explora un posible origen del Joker y sitúa a Batman en uno de los peores escenarios para un héroe, ver lastimados a sus colegas y seres queridos. En esta historia Barbara Gordon, alter ego de Batgirl, termina inválida y abusada por el Joker, mientras su padre Jim Gordon es obligado a ver todo el ultraje en una serie de fotogramas. El guión lleva a todos los personajes al límite y en un final anticlimático la locura de Batman y el Joker se aúnan en una última carcajada ${ }^{2}$ asesina. La oscuridad es la marca de estas historias que se alejan sustancialmente de una mirada trivial del personaje de malla y capas, sin embargo, vale la pena señalar que todas estas formas de volver a pensar a Batman llegan siete, diez e incluso treinta años después de la percepción que Lihn detenta con su versión paródica, capaz de exponer el enrevesamiento político e íntimo del hombre murciélago. Modo literario para nada inusual en Lihn pues el autor se enfoca en las fisuras y potencialidades del héroe, similar a lo que hace en poesía con Narciso y en narrativa breve con personalidades como el Caín bíblico.

El escritor toma estos sujetos míticos, ya sean de la cultura clásica o el pop y los actualiza con su usual dosis de cháchara y absurdo, en ese sentido Roberto Merino en la introducción a la re-edición de Batman en Chile (Bordura, 2008), establece un argumento que transcribo y que permite reforzar vasos comunicantes entre textos que tienen en común, el perseguir la deformación y re-semantizar idearios gracias a la apropiación de actantes estridentes: "El Chile visitado por Batman parece ser el reino de la cháchara tal como lo sería después la República Independiente de Miranda, en cuyo escudo heráldico campeaba un papagayo sobre el lema 'por angas o mangas"' (8).

Es preciso anotar lo que dice Lázaro Altamirano con respecto a la presencia intertextual de actantes de la cultura pop y del comic en la literatura u otros medios artísticos por años cerrados al discurso de masa debido a un carácter elitista y snob:

Si los clásicos en su momento tomaron a los dioses y héroes de su época como motivo de inspiración, ahora los escritores contemporáneos lo hacen con los héroes de su tiempo. Aunque algunos enfoques apunten a una intertextualidad

2 The Killing Joke ha sido tan polémica y abierta a múltiples interpretaciones, que el destacado autor Grant Morrison ha dicho en una entrevista (podcast) con Kevin Smith titulada Fatman on Batman, lo siguiente: "Es por eso que la conocemos como La broma asesina. El joker le cuenta la broma asesina, al final de la historia, Batman lo alcanza y le quiebra el cuello y por eso es que la carcajada acaba y la luz se apaga, pues esta fue la última chance de cruzar el puente. Alan Moore escribió la última historia de Batman y el Joker. Le puso un final" (La traducción es mía). Sea cual sea la interpretación que aceptemos para entender el fin de The Killing Joke, es claro que esta obra plantea la dualidad y lleva la relación de ambos personajes a cruces en que los roles de justiciero y sociópata se traslapan. 
que remite a la nostalgia, la imagen de la cultura popular se vuelve referente directo de intertextualidad, más aún porque los cómics están vinculados con la imagen (“El mito trágico de Batman"190).

Si hacemos un parangón entre Batman en Chile y la colección de cuentos La República Independiente de Miranda, especialmente con el relato Entre Caín y Abel podemos destacar desde el primer párrafo de la re-escritura bíblica, cómo esta narración construye su diégesis del mismo modo que la novela que nos convoca, desacralizando una figura y sus simbolismos, en este caso lo básico del libro sagrado: "Desde que mis padres inventaron la muerte y yo el crimen, no ha pasado una eternidad: ha pasado, en poco tiempo, cientos de años" (125).

Rápidamente el escritor da rienda a su juego de desmitificar al personaje al plantearnos la atmósfera en que verdaderamente discurre la historia y discurso de Caín, no cualquier Caín en todo caso, sino Caín González de la Sota cuyo espacio vital es propio de un hombre moderno, ligado en gran medida a los cuestionamientos de un intelectual errabundo y cosmopolita de paso por los Estados Unidos. La alusión a calles, universidades y el empleo de ciertos extranjerismos, nos remontan a la poesía que el autor presenta en A Partir de Manhattan y otros libros de su autoría como Pena de Extrañamiento. Bajo una satírica mirada, emerge la alusión a un sistema de vida degradado y autodestructivo: prostitutas, depresión, quiebra monetaria, vida disipada que también en un sentido dionisiaco se entrelaza con aquellos parajes y momentos de la escritura, propia de los textos fundacionales:

[...] yo era un becario de la Universidad de Columbia. Aprendía el inglés, me distraía de mi desesperación frecuentando, con una Biblia en el bolsillo, los bares y prostíbulos, si así pueden llamarse a esas sucursales en el Village de Sodoma y Gomorra, en las cuales existe un margen de gratuidad, hasta de inocencia ( $\mathrm{La}$ républica independiente de Miranda 126).

La oposición es evidente, Sodoma y Gomorra y lo que estos nombres comprenden connotativamente se mezcla con el estilo de vida de esta versión de Caín, sus costumbres y las calles perdidas y periféricas que recorre en la ciudad o en los extramuros del paraíso como declara para luego vaciar su lúcida y desencantada mirada al racionalismo y la consecuente crisis psicológica que pesa sobre sus hombros. La re-escritura que Lihn hace de Caín se detiene a través de un cínico discurrir en el proyecto racionalista, la otra gran utopía, el sueño de Rosseau y su evidente caída: "Se supone que el arrepentimiento y la tentación me han enloquecido. Que mi existencia es un suicidio diferido y consumado a la vez, de día en día" (130).

Al cerrar su discurso, el texto presenta dos afirmaciones que nos envuelven a todos como parte de la misma trágica broma, como parte intrínseca de un mundo en decadencia. Pese a cualquier tipo de evasión o negativa que pretendamos oponer, formamos parte del decurso de Caín, de su escritura frenética de la realidad: "Es así 
pero de otra manera. En alguna parte soy una celebridad; he escrito libros que todos leen sin saberlo, impresos en el aire" (Ibíd.).

\section{Humor conceptual y la deformación histriónica}

En Batman en Chile, Lihn opera de modo afín al proceso recién expuesto. La trama nos desnuda a un superhéroe que sufre desde un comienzo la confusión de una pesadilla subdesarrollada que su mente de primer mundo, jamás terminará de comprender:"El hombre murciélago anhelaba un enfrentamiento con los pillos, sólo que una especie de escepticismo sutil empezaba a hacer presa de él con respecto a la posibilidad real de ese enfrentamiento [...] ¿Quiénes eran aquí los verdaderos representantes de la ley y el orden? ¿Dónde estaba el enemigo?” (35).

La incursión al país latinoamericano a intervenir, o la colonia, como usualmente Batman nomina a Chile dentro de la novela, acarrea sistemáticas y absurdas vejaciones y desavenencias que minan su identidad hasta situarlo en el rol de sujeto descentrado y lleno de fisuras a nivel íntimo. A tal grado que terminamos por compartir las experiencias de un meteco o extranjero de baja categoría vagando como testigo patético en un contexto ambivalente:

Preservar su cuerpo, perder su alma, convertirse en un Americano, en todo un Americano con su gigantesca dosis de deficiencias, siempre que ellas les garantizaran la programación de su existencia, la adaptación a un sistema. E, incluso, deseaba ser Batman, si esta era la única alternativa, el único remedio, el único veneno. Pero otra vez, lejos de aquí (162).

En tal medida el flaneur, la incomunicación, la opacidad del signo y el sentimiento perpetuo de extranjería como una revelación ligada a la finitud, la nostalgia y el proceso de escritura, temas tan caros para Lihn y parte esencial de su producción literaria, no resultan ajenos a esta producción, la cual además conjuga ese otro nivel de su quehacer, el humor estridente, la performance dramática y el histrionismo que subyace en la parodia deformante. Valga la metáfora que el mismo Lihn pone en boca de su versión del hombre murciélago: “[...] en este hermoso país y lo digo sinceramente pensando en usted, las líneas divisorias son imprecisas. Desenmascarar a quienquiera que sea -usted sabrá perdonarme esta ruda expresión- es algo así como pretender pelar una cebolla arrancándole cada una de sus telas" (97).

Batman al inverso de la cita, es pelado por Chile como una cebolla, pierde capa, máscara, cinturón, incluso a su fiel compañero o sidekick. Robín. El chico maravilla, decide enfrentar al comunismo lejos de su mentor, en el turbulento contexto de la guerra de Vietnam, situación que persigue a Batman durante toda la obra como una ausencia trágica de dimensiones griegas, lo que sumado a las otras forzadas carencias penetra la solidez del Caballero de Ciudad Gótica y al final nos expone el núcleo feble 
bajo el emblema de justicia y vigilancia: "El pecho del superatleta se le aparecía ahora como la fachada de un edificio de tal manera abandonado que resultaba difícil que alguien estuviera lo bastante ciego como para golpear su puerta” (82).

Los despojos del hombre murciélago, revelan a un disminuido y confuso Bruno Díaz (en la versión original Bruce Wayne) que resulta en último término el verdadero disfraz o mero receptáculo. Un significante trunco para un mensaje y discurso que no logra ser incubado y menos germinar en este rincón del mundo, en que el comunismo opera constitucionalmente y la oposición se vale del crimen y oscuras intrigas para desestabilizar al poder y la libertad de prensa. Dantzler nos indica en su trabajo sobre la evolución de Batman y su audiencia, el siguiente pasaje revelador del personaje:

Los extremos del personaje de Batman así como lo dual en su identidad de Caballero Oscuro y Bruce Wayne, agrega profundidad y dimensión a su figura. Promover lo diverso no es inusual en el extraño mundo de los superhéroes, de hecho el exceso es una de las características definitorias del género. Ellos conviven en un universo de músculos inflados, lágrimas masculinas y la exposición al melodrama novelesco. El sentimiento de exageración en historias más grandes que la vida misma, juega un rol crucial en los comics, y Batman trabaja una exageración de sí mismo, en especial como un símbolo que es preferible antes del hombre. Como Bruce le dice a Alfred en la película "Batman Inicia": La gente necesita ejemplos dramáticos para sacarlos de su apatía, no puedo hacerlo como Bruce Wayne, un simple hombre de carne y hueso, puedo ser ignorado, destruido, pero como símbolo... el símbolo es incorruptible, puedo perdurar. El símbolo de Batman puede ser más grande que el hombre con traje, se convierte en leyenda (15, la traducción es mía).

A partir de esta base, Lihn se adelanta a las miradas actuales de Batman y la crisis de su dualidad promoviendo la des-realización del superhéroe y la caída de su contenido ideológico. Lihn lo trabaja como ya señale en clave kitsch. De todas formas me interesa en este punto resaltar la presencia en la novela de un tipo de humor que se atribuye a Macedonio Fernández y que se conoce bajo el adjetivo de "conceptual". El argentino define su proceso del siguiente modo: "El desbaratamiento de todos los guardianes intelectivos en la mente del lector por la creencia en lo absurdo que ella obtiene por un momento, lo liberta definitivamente de su fe en la lógica [...] que nos dice todos los días: 'puesto que todos mueren, tú has de morir" (Pineda 48).

Este carácter de revisión a la lógica y forma de jocosidad intelectual que Linh comparte con los presupuestos de Macedonio, es anotado por María Berríos en torno a Batman en Chile en su artículo "Epígrafe -a partir de cinco ejemplos conocidos- de una estética de lo informe o Humor conceptual y desaparición”:

[...] el libro de Lihn sobrevive como un gesto sarcástico, haciendo realidad las pesadillas más disparatadas de Dorfman y Mattelart, en que mentes inocentes y tercermundistas son alienadas sin piedad por la ideología estadounidense. Batman en Chile parodia ciertas posturas paternalistas de algunos intelectuales 
de izquierda que se volvieron casi mesiánicos en su cruzada contra la infiltración imperialista, burlándose de su total incapacidad para considerar el potencial inventivo de la imitación" (293).

A su vez Oscar Barrientos Bradasic en su artículo "La novelística de Enrique Lihn: Imaginación razonada y asedio a la realidad" señala en torno a la prosa del autor:

una revisión de la narrativa escrita por Enrique Lihn revela ciertos rasgos del género imaginativo y fantástico que se enlazan con la idea de alegorizar la realidad sin documentarla en forma directa. Es ahí, donde se descubre una obra de imaginación razonada que asedia (a través de la reinvención) las variadas caras de la realidad, incluso desde una perspectiva crítica (Párr. 7).

Las citas expuestas y lo dicho hasta este punto, buscan reforzar una noción de Lihn o al menos de parte de su producción literaria ubicada dentro de lineamientos que construyen un humor basado primero en el absurdo consciente o una razón de la ilogicidad amparada en la atmósfera de confusión y chachara. En la obra, Lihn pone en boca de su narrador frases como estas: "Ningún camino llevaba ahora a Ciudad Gótica, el mejor de los mundos imposibles. [...] reclamando para sus actividades el privilegio contradictorio de una ilegalidad" (93).

De esos lindes del lenguaje y sus enredos se desprende la otra tarea del autor, actualizar los mitos, los actantes y las figuras o discursos hiperbolizando lo grotesco, pornográfico e híbrido:

De pronto, recordó intensamente al niño maravilla y lo vio, al mismo tiempo, sentado al piano en un rincón de la Baticueva, en el momento mismo en que Robín -otro detalle onírico pero todavía coherente- se aprontaba, con las manos crispadas sobre el teclado, a iniciar un concierto" Una de las polonesas de Chopin hizo su irrupción en la atmósfera antiséptica bañándola de aletargantes irradiaciones lumínicas. Como si hubiera descarrilado, allá en el cielo, un vagón cargado de Kriptonita Verde (102).

El pasaje recién transcrito expone lo onírico del oscuro subconsciente de Batman y una saturación del elemento kitsch al desplegar la imagen de su joven compañero tocando piano, vale la pena pensar en el atuendo colorido y a lo Peter Pan de Robín, lo cual nos posiciona en una mirada camp ${ }^{3}$. Exacerbación de lo afectado y teatral que pone de manifiesto la pomposidad y la sobredramatización de los conceptos, las modas y las imágenes. Una concertina de música clásica con iluminación verde fluorescente de la kriptonita. Esto claramente no es nuevo para Lihn, símbolo y culminación de

3 Hutcheon frente a Sontag concibe el camp no sólo como una operación del gusto (como un criterio estético) sino como un complejo proceso de resignificación que a través de un mecanismo paródico transforma los códigos de género en el momento de su recepción (no en su producción). 
estos excesos es Gerardo de Pompier, por ende el modelo que usa para su Batman es como ya indiqué al principio del artículo, una visión grotesca de los clichés y tópicos del personaje. En cuanto al contexto político en que sitúa a su protagonista, basta remitirnos al Chile de los 70 que como bien dice Roberto Merino:

El mundo circundante, en la época de la Unidad Popular, parecía en su momento saturado de acciones, pero en mayor medida de palabras. Como nunca abundaron los eslóganes, las declaraciones, las llamadas de alerta a las bases de los partidos, los manuales de concientización. Los debates televisivos y radiales eran protagonizados por lenguas de fuego (8).

Tampoco debemos subestimar en esta materia, la ácida mirada de Lihn ante la intelectualidad de ambos polos, basta remitirnos para tal caso a su artículo sobre el caso Padilla. Lihn al respecto nos dice:

La política cultural de Cuba se caracterizó, durante doce años, por su indefinición teórica y una flexibilidad práctica hasta excesiva, pero que servía a los fines de la Revolución. Mientras esta juzgó conveniente prestigiarse internacionalmente, no dejó de atraer a los intelectuales de los tres mundos; de preferencia a los que ahora llama Fidel Castro, "las ratas intelectuales" de "esas sociedades decadentes, podridas y carcomidas hasta la médula de los huesos por sus propias contradicciones (El circo en llamas 432)

Asimismo la siguiente cita de María Berrios en torno a la novela que nos ocupa, también es clarificadora:

La articulación específica entre cultura y política no es tan clara como el canon de la historia del arte latinoamericano quisiera hacernos creer. Aunque todos parecían estar de acuerdo en que la cultura en general era "buena para la sociedad", cada uno tenía ideas diferentes acerca de lo que constituía una verdadera cultura revolucionaria (proporcionando complejas ecuaciones de cómo debían considerarse la alta cultura, la cultura popular y la cultura de masas). En Chile, la derecha defendió ferozmente la cultura de masas, lo que facilitó a la izquierda el asumir una actitud severa y dogmática hacia las referencias extranjeras, especialmente la estadounidense. El ejemplo más obvio es el ensayo de Ariel Dorfman y Armand Mattelart Para leer al Pato Donald, reconocido por la teoría contemporánea postcolonial como uno de los primeros estudios de caso sistemáticos sobre colonialismo cultural (293).

Considerando estas últimas referencias, vale la pena detenerse y preguntar: ¿Por qué Lihn escoge a Batman como protagonista de su cruzada estrambótica por el Chile confuso de los setenta? Merino se aventura a señalar lo siguiente: 
Lihn demostró una energía sorprendente por iniciar proyectos que excedían el radio de la poesía [...] La idea de inocular en el escenario de la realidad social chilena a un individuo extremadamente ficticio, y no por heroico exento de ridiculez, delata la intención de forzar una situación imposible. En esta novela y en otras posteriores Lihn se empeñó en generar la inverosimilitud para mirar el mundo circundante a través de su prisma [...] Me pregunto por qué Lihn eligió a Batman, un paladín de segundo orden, como protagonista de su obra. Me imagino que no solamente por el disfraz - ya que este es común a todos los héroes infantiles norteamericanos-, sino también, acaso inconscientemente, por su vaga conexión con la literatura gótica y por su relativa humanidad (8-9)

En este punto podemos considerar tres variables como posibles respuestas a la gestación que Lihn tuvo frente a su texto definitivo. La primera opción pudo ser enfocarse de modo realista y soso en su idea central. Un agente de la CIA que llega a este extraño contexto que es el Chile de la Unidad Popular y en el transcurso de su misión verse afectado por los eventos llegando al punto de cuestionar su misión, los límites morales y cuánto de su participación no es un mero mecanismo de manipulación, revelándose en último momento su carácter de instrumento, sin embargo, esto carece de todo histrionismo y drama, tal como señala Mario Valdovinos en su texto "Narrativa vanguardista y experimental":

Batman en Chile tiene como las dos novelas restantes del poeta, La orquesta de cristal y El arte de la palabra, e incluso uno de sus dos volúmenes de cuentos, La República Independiente de Miranda, ese aire vanguardista y experimental -a falta de mejores nombres- que proponía Lihn en sus narraciones. A saber: romper la linealidad del relato, pulverizar en lo posible el realismo, escamotear las descripciones y la ambientación naturalista, emplear un tipo de narrador que ironice el acontecer en el que se mueven personajes esperpénticos (Párr. 2).

Lihn elige trabajar con un personaje inusual, para ello que mejor que retratar desde el comic mismo, la paranoia de sus pares intelectuales antes los productos de masas, los personajes del género de superhéroes y la educación sentimental que ejercen como producto cultural sobre los más jóvenes. Esto lo podemos complementar con el rol que el noveno arte tuvo, por nombrar un caso, durante el periodo de entreguerras al combatir ideológicamente a Hitler, el fascismo y otros enemigos de la democracia según la versión de Norteamérica. Al respecto Coma comenta:

Así mientras muchos personajes tradicionales vestían el uniforme y marchaban al frente para combatir al enemigo (y otros lo hacían en la retaguardia como Charlie Chan o Dick Tracy, persiguiendo a espías y saboteadores), la coyuntura bélica sirvió para alumbrar el nacimiento de nuevos héroes, surgidos al amparo de aquellas circunstancias. El más famoso iba a ser Captain America (1941), escrito por Joe Simon y dibujado por Jack Kirby (Historia de los cómics 305). 
Para el caso del Chile de la guerra fría, la elección más usual sería un paladín que represente con su iconicidad y colores la bandera del país del norte, Superman por ejemplo, sin embargo, este no posee la humanidad y por ende la frágil psicología que le otorga a Lihn la posibilidad de desmenuzar al personaje, e incluso establecer relaciones de tipo edípicas y trastornos oníricos como los que manipula entre Robin y Batman. La elección más acorde sería Capitán América y su compañero Bucky, ambos portan como un estandarte móvil o logo andante los valores patrios de U.S.A, pero aquí nos topamos con otro tipo de linealidad discursiva tan ajena al discurso del autor. Como signo representante de una visión maniqueista y pragmática de la justicia, Steve Rogers o Capitán América es transparente y una elección demasiado obvia para explotar la retórica demagógica del medio y el miedo imperante en aquellos años. Hay que contar además el desconocimiento masivo del personaje en Latinoamérica, dada la escasa distribución de los comics de Marvel en esos años y la ausencia del personaje en la televisión. Estos cuestionamientos también son apuntados por María Berríos en su artículo "Undocumented Rumours and Disappearing Acts from Chile", publicado en la revista Afterall:

Incluso la elección de Batman como paradigma de todos los héroes americanos es inconsistente. Batman es un vigilante y técnicamente no un superhéroe pues carece de superpoderes, además es el más oscuro de los personajes estelares del comic norteamericano. Una elección más apropiada habría sido Superman o mejor todavía, Capitán América, como si fuera poco Lihn adopta la mirada camp televisiva de los sesenta en lugar de la versión, pulp y de misterio que se puede enraizar con la versión primigenia del personaje. La novela por tanto puede considerarse como el anverso del bullado caso Padilla, en la medida que Lihn escribió Batman en Chile mientas se refería abiertamente en contra de las políticas culturales de Cuba y su persecución a los intelectuales, por lo tanto mantiene una férrea defensa al rol crítico del artista (100, la traducción es mía).

\section{Conclusión}

Podemos concluir que la elección de Lihn de situar a Batman en Chile y por ende como protagonista de su novela, está orientada por el carácter humano y performático del personaje. Elección conflictiva e impensada para Berrios y extravagante para Merino, pero al fin y al cabo la que da vida a la obra que conocemos. En ella Lihn como ya señalé, dota al personaje de conflictos que el cómic americano aún estaba reconociendo o explorando tímidamente, y a su vez constituye una novela latinoamericana de alto contenido político y reflexión ante los poderes que dominan la realidad como la conocemos, claro sin descuidar su obsesión por la opacidad del signo, representado por un héroe que pondera el exceso de dramatismo al travestirse de murciélago. Al respecto Yvette Sánchez nos dice 
Batman no posee poderes sobrehumanos, es decir que no puede, como otros superhéroes, atravesar muros o vidrios, sin dejar atrás una estela de destrucción. En cambio, Bruce Wayne se ha decidido por el atuendo de murciélago, porque en una escena clave, onírica, meditativa, irrumpió en su biblioteca un murciélago rompiendo el cristal. Además el Caballero de la Noche se ha entrenado especialmente para el camuflaje (270).

Si ponderamos este último factor de encubrimiento e incomunicación, vale pensar para los fines de Lihn, que mejor que uno de los personajes más oscuros del universo DC. Aquel de naturaleza humana a diferencia de sus pares, y que por voluntad propia escoge vestirse como un mamífero alado e hiperbolizar lo gótico con el fin de infundir pavor en el corazón de los que atacan a los débiles y que él observa como una repetición constante y proyección de quienes mataron a sus padres durante su infancia, sin embargo, hay que señalar que en la novela de Lihn, la oscuridad no es unilateral en el sentido propio de una atmósfera ad hoc para los fines del vigilante. La realidad que el escritor edifica y en la cual sitúa la voz protagónica, detenta otro tipo de ilegibilidad, a tal grado que llega a envolver y superar al oscuro personaje de ficción. La realidad se vuelve una pesadilla para un personaje que termina superado por su exceso de pragmatismo. Por ejemplo, la imitación que Lihn hace en su escritura, de los cartuchos ${ }^{4}$ a manera de frases tópicas que permiten diálogos internos de los personajes o marcaciones temporales como elipsis, flash backs, raccontos o flash forwards y desde luego cambios de escenario entre viñetas: "mientras tanto" o "en otro lugar de la ciudad”, parecen estar destinados sólo a Batman y no a quienes lo rodean, de modo que su sueño de mundos imposibles jamás retornará a la simpleza del sueño americano, hoy imposible de habitar.

El anticlímax de todo esto es la desnudez del héroe, su situación de meteco, intruso no querido o simple extranjero ramplón detentador de todos los clichés imaginables. Así acaba el mito y fluye el terror que una sociedad disfrazada e hipócrita en su coherencia, infunde a la identidad real o disfraz de hombre que no está preparado para la aventura y que en el espejo del sueño se muestra en su completa indefensión al tiempo que nos grafica los impensados ángulos de la realidad, geometrías y geografías increíbles que denuncian la aberración del poder y la descarnada lucha capaz de aplastar y hundir a cualquier héroe, pues la ilegalidad dicotómica o maniquea a combatir no existe y nada es lo que se dice o lo que se dice, es un simple abismo sin fondo:

Habiéndose retirado a buen compás de pies a sus habitaciones privadas, como en sus mejores tiempos de hombre murciélago, Bruno Díaz concilio un sueño

4 El cartucho o cartela es un cuadro de texto situado dentro de una viñeta o entre dos de ellas, con la función de explicar o narrar al lector determinados hechos de la historia que debe conocer. Suelen aparecer en la primera viñeta de los cómics, a modo de introducción, y en ocasiones también en la última, como conclusión y para encerrar la palabra "Fin". 
sin alternativas, enteramente mediocre. Soñó que despertaba en ciudad gótica de una pesadilla de la que no lograba acordarse, relacionada con un país llamado Chile y con su lucha contra el comunismo. Todo eso tan lejano como el más remoto de los planetas (102).

Basta agregar lo que dice Lihn al respecto en su relato El hombre y su sueño:

Hay un punto en que el instinto y la razón, el sentimiento y el pensamiento, el sueño y la vigilia se asocian en un abrazo radiante. Mi vida no ha sido sino un largo y penoso intento de encontrarlo. Quienes como yo comprenden que sólo la exacerbación de la conciencia nos permitirá atravesar inmunes esta época de pesadillas aprobarán el sentido y el giro de mi aventura (281).

\section{Referencias}

Barrientos, Oscar. "La novelística de Enrique Lihn: imaginación razonada y asedio a la realidad”. Cyber Humanitatis 13 (2000). http://web.uchile.cl/publicaciones/ cyber/13/tx9.html. Fecha de ingreso: 4 de mayo de 2000. Sitio web.

Berríos, María. "Epígrafe - a partir de cinco ejemplos conocidos- de una estética de lo informe o Humor conceptual y desaparición”. Coloquios. Trienal de Chile. Ed. Nelly Richard. 293-294. 2009. Medio impreso.

---. "Undocumented Rumours and Disappearing Acts from Chile". Afterall 21. (verano 2009). Medio impreso.

Coma, Javier. Historia de los cómics. Barcelona: Josep Toutain, 1984. Medio impreso. Dantzler, Perry Dupre. "Static, yet fluctuating: the evolution of Batman and his audiences". English Theses. Paper 73 (2009). Georgia State University. http://scholarworks. gsu.edu/cgi/viewcontent.cgi?article=1072\&context=english_theses. Fecha de ingreso: 17 mayo de 2014. Sitio web.

Eco, Umberto. Apocalípticos e integrados. Trad. Andrés Boglar. España: Tusquets, 2001. Medio impreso.

Darowski, John. "The mythic symbols of Batman”. Department of Comparative Studies. Brigham Young University (2007). http://scholarsarchive.byu.edu/cgi/ viewcontent.cgi? article $=2225 \&$ context $=$ etd. Fecha de ingreso: 9 de junio de 2014. Sitio web.

Lafourcade, Enrique. Antología del Nuevo Cuento Chileno. Santiago: Zig-Zag, 1954. Medio impreso.

Lazaro, Saúl. "El mito trágico de Batman”. 452F 3 (2010).186-197. http://www.452f. com/es/saul-lazaro.html. Fecha de ingreso: 5 de mayo de 2014. Sitio web.

Lihn, Enrique. Batman en Chile o El ocaso de un ídolo o Solo contra el desierto rojo. Santiago: Bordura, 2008. Medio impreso.

---. El circo en llamas. Santiago: LOM, 1996. Medio impreso. 
---. Huacho y Pochocha. Buenos Aires: Sudamericana, 2005. Medio impreso.

---. La República Independiente de Miranda. Buenos Aires: Sudamericana, 1989. Medio impreso.

Maquiavelo, Nicolás. "Discursos sobre la Primera Década de Tito Livio". Obras Políticas. Trad. Luis Navarro. Buenos Aires: El Ateneo, 1952. Medio impreso.

Morrison, Grant. "Fatman on Batman \# 044". More with Morrison (14 de agosto, 2013). http://smodcast.com/episodes/more-with-morrison. Fecha de ingreso: 2 de abril de 2015. Sitio web.

Narváez, José. Razón de Estado y razón de justicia (2008). Global cinema. http://www. jgcinema.com/single.php?sl=dark-knight-razon-de-estado. Fecha de ingreso: 3 de mayo de 2014. Sitio web.

Pineda, Carlos. "El humor conceptual de Macedonio Fernández". Casa del Tiempo 92 (2 de septiembre de 2006) 47-49. México: UAM. Medio impreso.

Sánchez, Yvette. "Batman entre las mariposas. Arte coleccionista o el riesgo de transgredir el orden". Carlos Pazos-No me digas nada Ausstellungskatalog. Barcelona: MACBA (Museu d'Art Contemporani de Barcelona) und Museo Nacional Centro de Arte Reina Sofía, 2007. Medio impreso.

Valdovinos, Mario. "Narrativa vanguardista y experimental". Revista de Libros de El Mercurio. (30 de agosto 2009). Recuperado de http://letras.s5.com/el010909. html. Fecha de ingreso: 23 de junio de 2014. Sitio web.

Recibido: 13 junio 2013 Aceptado: 21 septiembre 2014 